\title{
The Management of Madness
}

\section{Wylie Jones Jordan*}

Travis County Medical Society and The Texas Association of Psychiatric Physicians, USA

*Corresponding author: Wylie Jones Jordan, Travis County Medical Society and The Texas Association of Psychiatric Physicians, USA, Tel: 52-74 44-82-10-40; E-mail: wyliejjordan@gmail.com

Received date: September 22, 2016, Accepted date: October 06, 2016, Published date: October 17, 2016

Copyright: ( 2016 Jordan WJ. This is an open-access article distributed under the terms of the Creative Commons Attribution License, which permits unrestricted use, distribution, and reproduction in any medium, provided the original author and source are credited.

\begin{abstract}
Roman physician Claudius Galen recognized two types of disabling mental illness, madness and melancholia. He believed these disorders were caused by humoral imbalance and often prescribed bleeding as a method of relieving the most severe symptoms. Many other methods of symptom control have been tried and the names have changed and multiplied, but the causes are no better known today than they were to Galen. 'Madness' (now several kinds of schizophrenia) is filed under international code \#295 and 'mania' (an even greater number of named mood disorders) under \#296.
\end{abstract}

'What's in a name? That which we call a rose

by any other name would smell as sweet.'

Wm. Shakespeare. Romeo and Juliet (II, ii, 1-2)

Keywords: Psychosis; Mania; Schizophrenia

\section{Introduction}

Galen is believed to have adopted Hippocrates' idea that there were four essential bodily humors that were related to the four elements of antiquity, the four seasons of the year, and the four ages of man. Humoral balance brought about health and disease was a result of imbalance. The humors were described by color: red (blood), white (phlegm), yellow (bile), and black (melena). The predominant humor determined the personality and, depending on the humor, a person might be described as sanguine (blood), phlegmatic (phlegm), choleric (bile), or melancholic (black).

Three of the humors - blood, phlegm, and bile (chole) - certainly exist, although their functions are not what Galen thought. The black bile (Greek: melaina, black+chole, bile) is the exception. Neither its source nor its constitution has ever been identified - but as yet no other cause of psychiatric disorders has been found to take its place.

Medical diagnosis before the end of the $19^{\text {th }}$ century was simply a description of the symptoms. The fevers were often named according to the place they first appeared, as in Cyprus or Neapolitan fevers (both brucellosis) or by the color of a symptom, such as scarlet, yellow, or black water fevers. Diseases which produced pus-filled blisters were called poxes.

Galen's treatments were intended to correct the balance of humors. Colds and respiratory illnesses, he said, were the result of too much white humor (phlegm) and might be relieved by the use of substances that caused sweating. Problems caused by excess yellow and black humors, including melancholia, should respond to laxatives and emetics. The most severe cases of madness were due to an excess of the red humor (blood), and bleeding was clearly indicated.
The humoral system worked well enough most of the time, and doctors had a ready excuse when it failed. Arnaud de Villeneuve (ca. 1235-1312) advised physicians to 'just mention obstruction because they do not understand what it means, and it helps greatly that a term is not understood by the people' [1]. The idea of a 'humoral obstruction' has been replaced by the notion of a 'chemical imbalance' but neither obstruction nor imbalance has been proved.

\section{Psychosis}

Karl Friedrich Canstatt is frequently credited with the coinage of the word psychosis (Gk psyche, soul+osis, abnormal) to describe Galen's madness and melancholia. Although Canstatt obtained his medical degree at the University of Wurzburg in 1831, he may never have treated mental patients. His study of Asiatic cholera, published in 1832, led to the management of a cholera hospital, and in 1838, he moved to Regensburg to practice ophthalmology.

The American Psychiatric Association no longer provides a definition of psychosis but the word continues in common use despite the lack of consensus as to its meaning. The first Manual [2] defined 'psychotic disorders' as 'characterized by a varying degree of personality disintegration' and 'failure to test and value correctly external reality in various spheres'. The second edition suggested that patients could be described as psychotic when their mental functioning is sufficiently impaired to interfere grossly with their capacity to meet the ordinary demands of life [3].

The third edition of the Manual gave no definition of psychosis but said that 'schizophrenic disorders' are characterized by the presence of certain psychotic features [4]. The most recent nomenclature says that a number of poorly defined symptoms including delusions, hallucinations, disorganized speech or abnormal motor activity are 
considered indicative of 'schizophrenia spectrum' and other psychotic disorders [5].

\section{Mania}

German psychiatrist Emil Kraepelin [6] was born in the Duchy of Mecklenburg-Strelitz. He began his medical studies at age 18 in Leipzig and received his medical degree in 1878. The following year he enrolled in the University of Munich, where he completed his thesis, 'The Place of Psychology in Psychiatry'.

Kraepelin resurrected Galen's two kinds of severe mental disorders. $\mathrm{He}$ thought patients whose most prominent symptoms were hallucinations and delusional thinking - madness - should be described as suffering from 'dementia praecox' (i.e., premature) while those whose most outstanding symptom was excitability or depression - melancholia - were better labeled by a diagnosis of 'mania'. The diagnosis of mania was for a time called 'manic depressive illness' [7] or 'mood disorders'. The name changed again, to 'major depressions' and 'bipolar disorders' and the latest Manual lists 36 varieties under 32 different code numbers [8], all fined under DSM-5 code \#296.

\section{Schizophrenia}

Swiss psychiatrist Paul Eugen Bleuler [9] differed with Kraepelin, saying that' dementia praecox' was neither dementia nor precocious. Bleuler believed that a 'splitting' of mental functioning was the essential feature of insanity, and coined the word 'schizophrenia' (Gk. schizo, split+phren, mind) to replace 'madness' and 'dementia praecox.' Schizophrenia has subsequently been listed under as many as 29 different names [10] but the latest Manual lists only four varieties. All the 'schizophrenias' are filed under DSM-5 code \#295.

Bleuler was born near Zürich and studied medicine there. Following graduation in 1881, he worked as a medical assistant at the Waldau Psychiatric Clinic in Bern and, in 1898 was appointed director of the Burghölzli university hospital. Bleuler was initially interested in Sigmund Freud's theories, but came to believe they were dogmatic and, in 1911 resigned from Freud's International Psychoanalytic Association, saying that 'this all or nothing is in my opinion necessary for religious communities and useful for political parties...but for science I consider it harmful [11].

\section{Schizoaffective Disorder}

Although authorities generally agree there is an important difference between 'schizophrenia' (madness) and 'major depression' (melancholia), the distinction is far from clear. The American Psychiatric Association suggests an intermediate definition of 'schizoaffective disorder' for patients whose doctors are unable to decide which category is more appropriate for a given patient [12].

\section{Insanity}

In the $19^{\text {th }}$ century a common medical diagnosis for madness was insanity, but that word was abandoned after a famous murder. A Scot named Daniel MacNaughton had come to believe the British government was planning to kill him. His fears were focused on the Prime Minister, Sir Robert Peel [12], who created the modern police force. Police officers even today are called 'bobbies' in England and 'peelers' in Ireland.
Mac Naughton, in what he probably thought was self-defense, took a shot at Peel, but his aim was poor and he killed the Prime Minister's secretary, Edward Drummond, instead. In 1843, Mac Naughton was tried for murder but found not guilty by reason of insanity.

Queen Victoria was dissatisfied with a verdict that seemed lenient for what she saw as an assault on the Crown. She demanded a definition of insanity and her ministers soon provided one, known as the MacNaughton Rule. Under the Rule, a defendant should be considered sane unless, 'at the time of committing the act, the accused was laboring under a defect of reason so as not to understand the nature and quality of the act or, if the defendant did know it, did the defendant not know that the act was wrong?'

In almost 200 years following the McNaughton trial, many jurisdictions have amended the Rule or proposed other definitions of insanity, but none seems more practical than asking jurors to decide if according to the Rule a defendant should be considered sane and responsible, or not. A woman who turns her car into a weapon and runs over her husband must know what she is doing and should be judged sane, but one who drowns her children to protect them from the devil probably is not.

\section{Dementia}

A legal definition of insanity meant that lawyers, not physicians, owned the diagnosis, and psychiatrists have avoided the word ever since. The American Journal of Insanity became The American Journal of Psychiatry (Gk. psyche, soul + iatros, physician) and the diagnosis of 'insanity' turned into 'dementia' (L. de-, without + mens, mind), but word dementia is no longer part of any functional diagnosis. Dementia is still a part of several organic disease diagnoses including boxer's dementia, vascular dementia, and pre-senile (Alzheimer's) dementia.

\section{References}

1. Arikha N (2007) Passions and Tempers. A History of the Humors. HarperCollins, New York. pp: 85.

2. (1952) Diagnostic and Statistical Manual of Mental Disorders (DSM-I). (2nd edn.) American Psychiatric Association, USA. Pp: 24.

3. (1968) Diagnostic and Statistical Manual of Mental Disorders (DSM-II). American Psychiatric Association, USA. pp: 23.

4. (1980) Diagnostic and Statistical Manual of Mental Disorders (DSM-III). American Psychiatric Association, USA. pp: 181.

5. (2013) Diagnostic and Statistical Manual of Mental Disorders (DSM-5). American Psychiatric Association, USA. pp: 67.

6. Ebert A, Bär KJ (2010) Emil Kraepelin: A pioneer of scientific understanding of psychiatry and psychopharmacology. Indian J Psychiatry 52: 191-192.

7. (1968) Diagnostic and Statistical Manual of Mental Disorders (DSM-II). American Psychiatric Association, USA. pp: 36-37.

8. (2013) Diagnostic and Statistical Manual of Mental Disorders (DSM-5). (5th edn.) American Psychiatric Association, USA. pp: 67.

9. Ashok AH, Baugh J, Yeragani VK (2012) Paul Eugen Bleuler and the origin of the term schizophrenia (SCHIZOPRENIEGRUPPE). Indian J Psychiatry 54: 95-96.

10. (1968) Diagnostic and Statistical Manual of Mental Disorders (DSM-II) American Psychiatric Association, USA. pp: 510.

11. Peter G (1989) Freud: A Life for Our Time. (1st edn.) W. W. Norton \& Company, USA. pp: 215.

12. http://www.historic-uk.com/HistoryUK/HistoryofEngland/Sir-RobertPeel/. 